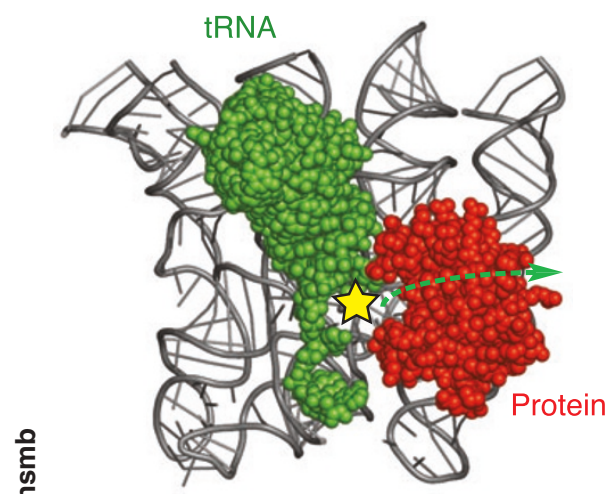

Figure 2 Model of the RNase $\mathrm{P}$ holoenzyme. RNase P protein (red) and tRNA (green) are modeled on the B-type RNase P RNA (gray ribbon) on the basis of predicted contact sites identified by footprinting and crosslinking data. The yellow star marks the predicted site of catalysis and the green dashed arrow indicates the path of the precursor tRNA's $5^{\prime}$ leader sequence, which is removed by RNase P cleavage. Figure provided by A. Kazantsev and N. Pace.

bound their cognate and noncognate proteins equally well and each protein protected a patch on the RNA comprised of conserved residues involved in tertiary interactions. This patch is adjacent to the active site (Fig. 2), so Buck et al. propose that protein binding may directly alter local RNA structure near the tRNAbinding site and thereby modulate substrate recognition and binding. The way in which these structural changes affect catalysis is not yet fully understood. As catalysis can occur in vitro without the protein, one must wonder whether the mechanism of cleavage by the holoenzyme is the same as that by the RNase P RNA alone.

These data collectively show that a comprehensive understanding of even a one protein/ one RNA RNP requires systematic and comparative biochemical, biophysical and structural analysis. We now have a much better idea of what the bacterial RNase P looks like and understand how the structures of the components dictate their relative contributions to assembly of the holoenzyme. These are highly important steps forward in understanding the catalytic mechanism and the way in which this universally conserved enzyme assembles and functions in bacteria. They lay the essential groundwork for understanding the mechanism of cleavage by RNase P. Furthermore, they will inspire additional experiments on the more complex archaeal and eukaryotic RNP enzymes and provide much food for thought for the rest of us examining our favorite RNPs.

1. Altman, S. \& Kirsebom, L. Ribonuclease P. in The RNA World 2nd edn (eds. Gesteland, R.F., Cech, T.R. \& Atkins, J.F.) 351-380 (Cold Spring Harbor Laboratory Press, Cold Spring Harbor, New York, USA, 1999).

2. Frank, D.N. \& Pace, N.R. Annu. Rev. Biochem. 67, 153-180 (1998).

3. Hartmann, E. \& Hartmann, R.K. Trends Genet. 19 561-569 (2003).

4. Xiao, S., Day-Storms, J.J., Srisawat, C., Fierke, C.A. \& Engelke, D.R. RNA 11, 885-896 (2005).
5. Xiao, S., Scott, F., Fierke, C.A. \& Engelke, D.R. Annu Rev. Biochem. 71, 165-189 (2002).

6. Kazantsev, A.V. et al. Proc. Natl. Acad. Sci. USA 102 , 13392-13397 (2005)

7. Torres-Larios, A., Swinger, K.K., Krasilnikov, A.S., Pan, T. \& Mondragon, A. Nature 437, 584-587 (2005).

8. Buck, A.H., Dalby, A.B., Poole, A.W., Kazantsev, A.V. \& Pace, N.R. EMBO J. published online 15 September 2005 (doi:10.1038/sj.emboj.7600805).

9. Buck, A.H., Kazantsev, A.V., Dalby, A.B. \& Pace, N.R. Nat. Struct. Mol. Biol. 12, 958-964 (2005)

10. Loria, A. \& Pan, T. RNA 2, 551-563 (1996).

11. Pan, T. Biochemistry 34, 902-909 (1995).

12. Fang, X.W. et al. RNA 7, 233-241 (2001).

13. Harris, M.E. et al. EMBO J. 13, 3953-3963 (1994).

14. Niranjanakumari, S., Kurz, J.C. \& Fierke, C.A. Nucleic Acids Res. 26, 3090-3096 (1998).

15. Biswas, R., Ledman, D.W., Fox, R.O., Altman, S. \& Gopalan, V. J. Mol. Biol. 296, 19-31 (2000)

16. Loria, A., Niranjanakumari, S., Fierke, C.A. \& Pan, T. Biochemistry 37, 15466-15473 (1998).

17. Rox, C., Feltens, R., Pfeiffer, T. \& Hartmann, R.K. J. Mol. Biol. 315, 551-560 (2002).

18. Tsai, H.Y., Masquida, B., Biswas, R., Westhof, E. \& Gopalan, V. J. Mol. Biol. 325, 661-675 (2003).

19. Reich, C., Olsen, G.J., Pace, B. \& Pace, N.R. Science 239, 178-181 (1988).

20. Tallsjo, A. \& Kirsebom, L.A. Nucleic Acids Res. 21 51-57 (1993).

21. Kurz, J.C., Niranjanakumari, S. \& Fierke, C.A. Biochemistry 37, 2393-2400 (1998).

22. Guerrier-Takada, C., Gardiner, K., Marsh, T., Pace, N. \& Altman, S. Cel/ 35, 849-857 (1983).

23. Waugh, D.S. \& Pace, N.R. J. Bacteriol. 172, 6316 6322 (1990).

24. Stams, T., Niranjanakumari, S., Fierke, C.A. \& Christianson, D.W. Science 280, 752-755 (1998).

25. Spitzfaden, C. et al. J. Mol. Biol. 295, 105-115 (2000).

26. Kazantsev, A.V. et al. Proc. Natl. Acad. Sci. USA 100 7497-7502 (2003).

27. Loria, A. \& Pan, T. Nucleic Acids Res. 29, 1892-1897 (2001).

28. Westhof, E., Wesolowski, D. \& Altman, S. J. Mol. Biol. 258, 600-613 (1996).

\title{
The off switch for HP1
}

Eukaryotic chromatin is organized into distinct domains that are important for the regulation of gene activity. For example, genes within heterochromatic domains are usually transcriptionally silent. The heterochromatin protein-1 (HP1) family members are crucial for the formation of heterochromatin and bind modified nucleosomes in which Lys 9 of histone $\mathrm{H} 3$ is trimethylated (H3K9me3). This interaction is important for recruiting HP1 to the chromosomes. During mitosis, a majority of HP1 is released from the chromatin, but the way in which HP1-chromatin association is regulated in a cell cycle-dependent manner had not been characterized. Two independent studies by Fischle et al. and Hirota et al. (Nature, advance online publication 12 October 2005, doi:10.1038/nature 04219 and doi:10.1038/nature042254) now address this question.

Fischle et al. show that the overall level of H3K9me3 is not altered during mitosis, suggesting that other factors cause HP1 to dissociate from the chromatin. One possible factor is the mitotic phosphorylation of H3 Ser10 (H3S10ph). Both Fischle et al. and Hirota et al. use antibodies specific for the dual modifications (H3K9me3S10ph) to show that H3K9me3S10ph is predominantly found in mitotic chromatin (bottom row). Notably, the occurrence

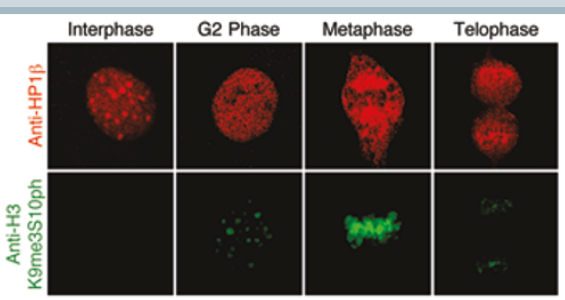

of the dual $\mathrm{H} 3$ modifications coincides with the release of HP1 from chromatin (top row).

It is known that $\mathrm{H} 3$ Ser10 is phosphorylated during mitosis by the chromosomal passenger complex (CPC) that contains the Aurora B kinase. Inhibition of Aurora B kinase by hesperadin (both studies), by RNA interference (both studies) or by depletion of CPC (Fischle et al.) produced mitotic chromatin that contained $\mathrm{H} 3 \mathrm{~K} 9 \mathrm{me} 3$ without Ser10 phosphorylaton. In these cases, HP1 failed to dissociate from chromatin, confirming the role of H3S10ph in regulating HP1-chromatin association. Using in vitro binding assays with $\mathrm{H} 3$ peptides, both studies show that phosphorylation of Ser10 is necessary and sufficient to induce HP1 release from mitotic chromatin. These results indicate that transient phosphorylation of $\mathrm{H} 3 \mathrm{Ser} 10$ during mitosis functions like an on/off 'switch', regulating the association of HP1 with chromatin. These studies support a previously proposed 'switch hypothesis' as a mechanism for regulating protein-protein interactions.

Hwa-ping Feng 